\title{
Enhanced Adherence of Streptococcus pneumoniae to Human Epithelial Cells Infected with Respiratory Syncytial Virus
}

\author{
JEANNE-MARIE HAMENT, PIET C. AERTS, ANDRE FLEER, HANS VAN DIJK, THEO HARMSEN,
} JAN L.L. KIMPEN, AND TOM F.W. WOLFS

Department of Paediatrics Infectious Diseases, Wilhelmina Children's Hospital, 3508 AB, Utrecht, The Netherlands [J.-M.H., P.C.A., A.F., J.L.L.K., T.F.W.W.] and Eijkman-Winkler Institute for Microbiology, Infectious Diseases and Inflammation, University Medical Centre, 3508 GA, Utrecht, The Netherlands [J.-M.H., P.C.A., H.v.D., T.H.]

\begin{abstract}
In the present study, we analyzed the effect of a preceding respiratory syncytial virus (RSV) infection of human respiratory epithelial cells on the adherence of Streptococcus pneumoniae tested by means of a cytometric fluorescence assay. Adherence of clinically relevant pneumococcal serotypes $3,9,14,18,19$, and 23 was studied using uninfected and RSV-infected monolayers. To this end, monolayers of both human nasopharyngeal cells (HEp-2) and pneumocyte type II cells (A549) were infected with RSV serotype A. Adherence to uninfected epithelial cells varied between pneumococcal serotypes. After RSV infection of the monolayers, all serotypes showed a strongly (2- to 10- fold) and significantly increased adherence when compared with adherence to uninfected monolayers. Enhanced adherence was ob-
\end{abstract}

\section{ABSTRACT}

served with both cell lines. By fluorescence and scanning electron microscopy, we observed redistribution of pneumococcal adherence over the epithelial surface due to RSV infection, with dense bacterial accumulations near to epithelial syncytia. (Pediatr Res 55: 972-978, 2004)

$\quad$ Abbreviations
RSV, respiratory syncytial virus
CPE, cytopathological effect
PFU, plaque-forming units
CFU, colony-forming units
IMDM, Iscove's modified Dulbecco's medium
MOI, multiplicity of infection

Streptococcus pneumoniae and RSV belong to the most important pathogens of upper and lower respiratory tract infections in young children $(1,2)$. There is accumulating evidence for a positive relationship between infections with $S$. pneumoniae and RSV, especially in the pathogenesis of otitis media, pneumonia, and meningitis (3-8). Epidemiologically, the peak incidences of RSV infections and invasive infections due to $S$. pneumoniae coincide (9). In a large study on the etiology of community-acquired bacterial pneumonia, a preceding viral infection could be detected by serology in $39 \%$ of the children (10). The combination of RSV and S. pneumoniae was seen most frequently in children below age $5 \mathrm{y}$.

The most prevalent pneumococcal serotypes causing invasive pneumococcal disease in children include serotypes 9, 14, 18, 19, and 23. Pneumococcal sepsis in adults is often caused by serotype 3 (11-14).

Received June 30, 2002; accepted December 17, 2002.

Correspondence: Tom Wolfs, M.D., Ph.D., Wilhelmina Children's Hospital, Room KE 04.136.2, Lundlaan 6, 3508 AB Utrecht, The Netherlands; e-mail: T.Wolfs@wkz.azu.nl.

DOI: 10.1203/01.PDR.0000127431.11750.D9
Enhanced pneumococcal adherence, secondary to a preceding RSV infection of the respiratory tract epithelium, is considered one of the mechanisms facilitating bacterial infection $(15,16)$.

The aim of the present study was to examine the influence of prior RSV infection on pneumococcal adherence to confluently grown epithelial cells using an assay based on adherence of fluorescent pneumococci. The influence of RSV-preinfection on pneumococcal superinfection with serotypes $3,9,14,18$, 19 , and 23 was evaluated.

\section{MATERIAL AND METHODS}

Bacteria. Clinical pneumococcal isolates, serotypes 3, 9, 14, 18, 19, and 23, were kindly provided by Dr. C. Neeleman, Intensive Care Department of the University Hospital of Nijmegen, The Netherlands, and stored at $-70^{\circ} \mathrm{C}$ in micro-banks (Pro-Lab Diagnostics, Austin, TX, U.S.A $>$ ). Before testing, an aliquot of stored bacteria was transferred from a micro-bank bead to blood-agar plates and was incubated overnight at $37^{\circ} \mathrm{C}$ in a $\mathrm{CO}_{2}$ incubator. The next day, the bacteria were inoculated in Todd-Hewitt broth (Difco, Detroit, MI, U.S.A.), supple- 
mented with $0.5 \%$ yeast extract and grown by static culture to logarithmic phase $(\mathrm{t}=6.5 \mathrm{~h})$ at $37^{\circ} \mathrm{C}$ in a $\mathrm{CO}_{2}$ incubator. This culture was washed twice in PBS and alternated with centrifugation at $9300 \times g$ during $2.5 \mathrm{~min}$ (Eppendorf centrifuge, International Equipment Company, Dunstable, U.K.). Next, the bacteria were suspended and incubated for $30 \mathrm{~min}$ in PBS $(2+) \mathrm{Ca}^{2+} 0.15 \mathrm{mM}, \mathrm{Mg}^{2+} 0.5 \mathrm{mM}$ with BSA $2.5 \% \mathrm{BSA}$; Instruchemie, Hilversum, The Netherlands) to prevent nonspecific binding. Three-hundred microliter samples of the bacteria were frozen in liquid nitrogen and were stored at $-70^{\circ} \mathrm{C}$ until use. For the cytometric fluorescence assay, bacteria heat-killed at $56^{\circ} \mathrm{C}$ for $30 \mathrm{~min}$ were used. In the adherence assay based on CFU counts, however, vital bacteria were used. In addition, for cytometric adherence experiments, pelleted heat-killed bacteria were labeled with saturated FITC solution $(0.5 \mathrm{mg} / \mathrm{mL}$ in PBS; Sigma Chemical Co., St. Louis, MO, U.S.A.), and incubated for $1 \mathrm{~h}$ at $4^{\circ} \mathrm{C}$, after which they were washed thrice with PBS. Before testing, the bacterial suspensions were suspended in PBS $(2+) / B S A ~ 2.5 \%$ and adjusted in a spectrophotometer to an OD $660 \mathrm{~nm}=0.1\left(\cong 1.0 \times 10^{8}\right.$ bacteria $\left./ \mathrm{mL}\right)$.

Virus. RSV serotype A (American Type Culture Collection, ATCC VR1302, Manassas, VA, U.S.A.) was kindly provided by Dr. A. Brandenburg (Department of Clinical Virology, University Medical Center Erasmus, Rotterdam, The Netherlands). An RSV dilution of 1:1000 in $70 \mathrm{~mL}$ IMDM (Invitrogen, Carlsbad, CA, U.S.A.) supplemented with HEPES ( $N-2-$ hydroxyethylpiperazine- $N$ '-2-ethanesulfonic acid, $25 \mathrm{mM}$ ), $5 \%$ FCS (Hyclone Laboratories, Logan, UT, U.S.A.) and gentamicin $0.01 \mathrm{mg} / \mathrm{mL}$ (Invitrogen) was added to monolayers of HEp-2 cells. At d 4 post-RSV infection, CPE became visible and supernatant was replaced by fresh IMDM. After $3 \mathrm{~h}$ of incubation at $37^{\circ} \mathrm{C}$, supernatant containing RSV was harvested and filtered through a $0.22-\mu \mathrm{m}$ filter. PFU were counted by the PFU assay according to Dulbecco. Stock aliquots were stored at $-180^{\circ} \mathrm{C}$ in liquid nitrogen, and they contained about $2.4 \times$ $10^{7} \mathrm{PFU} / \mathrm{mL}$.

Cell culture and viral infection of monolayers. HEp-2 human nasopharyngeal carcinoma cells (ATCC:CCL-23) and A549 cells, human pneumocyte type II carcinoma cells (ATCC:CCL-185) were used throughout the experiments. Stocks of cellular suspensions were stored at $-180^{\circ} \mathrm{C}$ in liquid nitrogen.

Tissue culture flasks (Costar, Cambridge, MA, U.S.A.), confluently grown with HEp-2 or A549 cells, were washed with PBS. A film of trypsin (Invitrogen) was added and the mixtures were incubated for a few minutes at $37^{\circ} \mathrm{C}$ to detach the cells. Subsequently, $10 \mathrm{~mL}$ IMDM was added. Before the cells were added, 50 or $250 \mu \mathrm{L}$ of a viral suspension was added to the wells of a 96-well microtiter plate (cytometric assay) or a 24-well plate (CFU-based assay) in a serial dilution or IMDM as control. The cell suspension was diluted to approximately 2 $\times 10^{5} / \mathrm{mL}$, and 50 or $250 \mu \mathrm{L}$ was seeded in all wells of the 96or 24-well plates. The microtiter plates were incubated for different periods at $37^{\circ} \mathrm{C}$ to allow formation of confluent monolayers until use.

Quantitation of RSV infection by immunofluorescence. RSV-infected HEp-2 cells and A549 cells (dilutions: $4 \times 10^{5}$ cells $/ \mathrm{mL}$ ) were grown in IMDM in 24-well plates (Costar) and incubated in $37^{\circ} \mathrm{C}$ in a $\mathrm{CO}_{2}$ incubator. After $3-5 \mathrm{~d}$ of RSV infection, monolayers were detached with trypsin, washed, and incubated for 15 min with $25 \mu \mathrm{L}$ FITC-labeled monoclonal anti-RSV antibodies directed against glycoprotein F (Imagen kit for RSV, DAKO, Bucks, U.K.) diluted 1:12.5 in PBS $(2+)$.

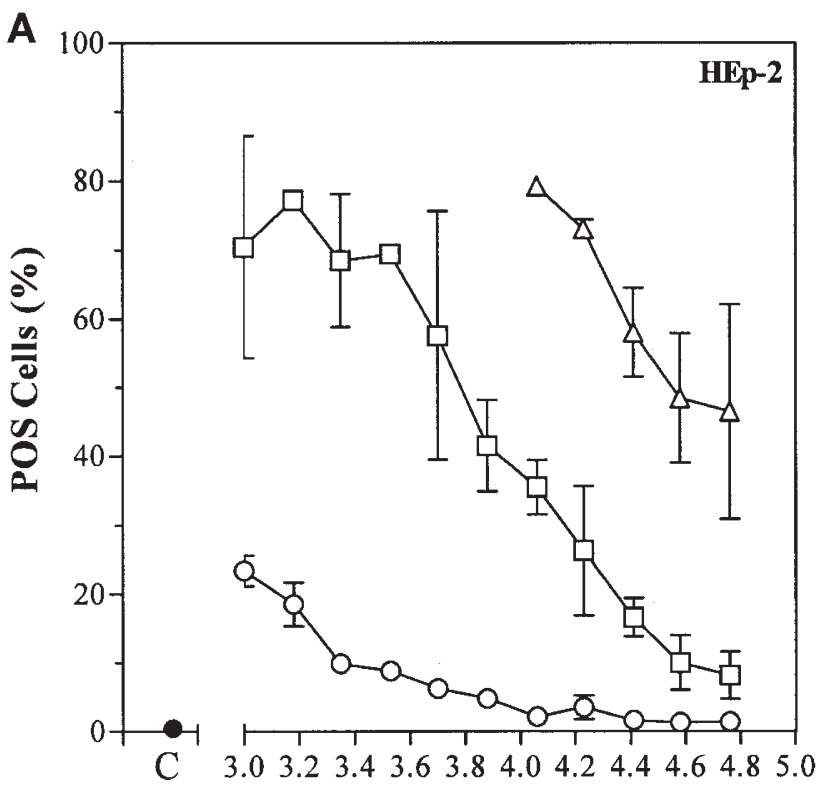

RSV dilution

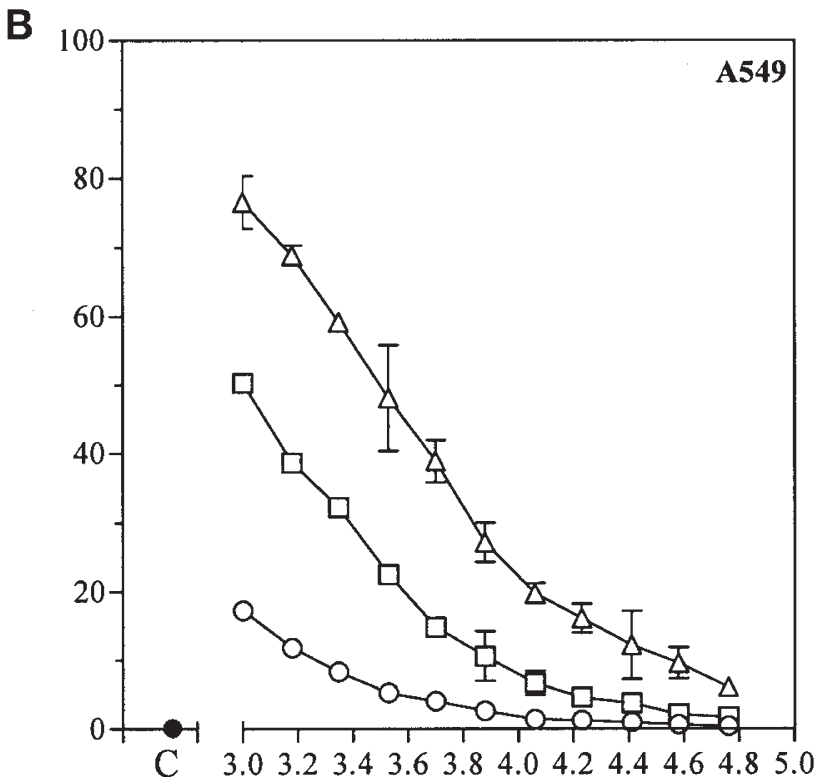

RSV dilution

Figure 1. RSV detection by FITC-labeled monoclonal anti-RSV antibodies directed against glycoprotein F: expression of RSV glycoprotein F on the cell surface of HEp-2 cells and A549 cells on d 3-5 post-RSV infection. (A) $x$ axis: logarithmic dilution of RSV, incubated with HEp-2 cells (viral logarithmic dilution ranging from 3.0 to 5.0 corresponds with MOI of $1.25 \times 10^{-1}$ to $\left.1.25 \times 10^{-3}\right) ; y$ axis: percentage of glycoprotein F-positive HEp-2 cells. $(B) x$ axis: logarithmic dilution of RSV, incubated with A549 cells; $y$ axis: percentage of glycoprotein F-positive A549 cells. $\odot=\mathrm{d} 3$ post-RSV infection; $\square=\mathrm{d} 4$ post-RSV infection; $\Delta=\mathrm{d} 5$ post-RSV infection; $C$, control (uninfected HEp-2 or A549 cells). Error bars represent means and ranges of duplicate samples. 


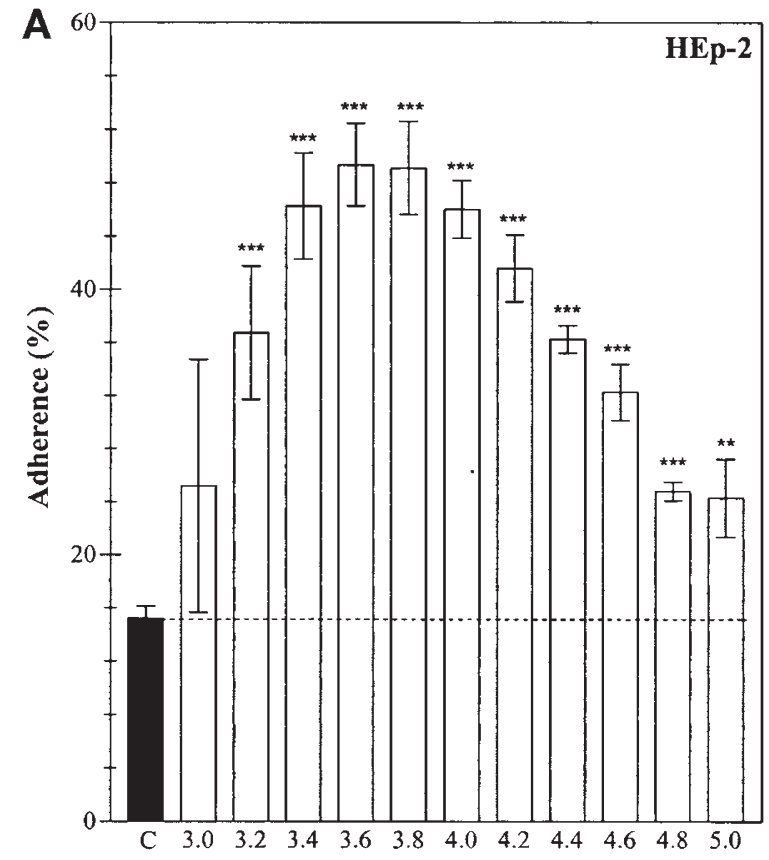

$\begin{array}{llllllllllll}100 & 35 & 45 & 75 & 80 & 95 & 95 & 95 & 95 & 100 & 100 & 100\end{array}$

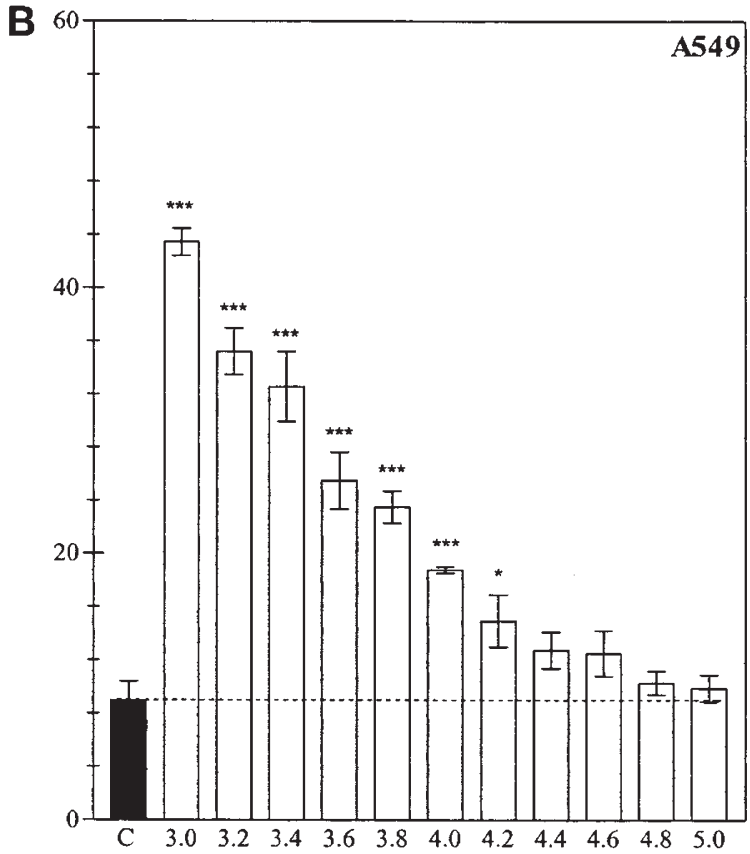

$\begin{array}{lllllllllllll}100 & 95 & 95 & 100 & 100 & 100 & 100 & 100 & 100 & 100 & 100 & 100 & \text { Monolayer (\%) }\end{array}$

Figure 2. Adherence of heat-killed S. pneumoniae serotype 14 to uninfected and RSV-infected HEp-2 and A549 cells as measured by the cytometric fluorescence assay.(A) Adherence of pneumococcal serotype 14 to HEp-2 monolayers. (B) Adherence of pneumococcal serotype 14 to A549 monolayers. $x$ Axis: logarithmic dilution of RSV incubated with HEp- 2 cells/A549 cells (viral logarithmic dilution ranging from 3.0 to 5.0 corresponds with MOI of $1.25 \times 10^{-1}$ to $1.25 \times 10^{-3}$ ); $y$ axis: percentage pneumococcal adherence. Filled bars: pneumococcal adherence to uninfected HEp-2 or A549 cells. Open bars: pneumococcal adherence to RSV-infected HEp-2 or A549 cells. Monolayer \% = percentages of remaining monolayer covering the well after the experiment, representing the extent of CPE $(80 \%$ means $20 \%$ cell loss of monolayer). Error bars represent SEM of three experiments; $* p<0.05, * * p<0.01, * * * p<0.001$ (significance of difference from controls assessed by $t$ test).

A

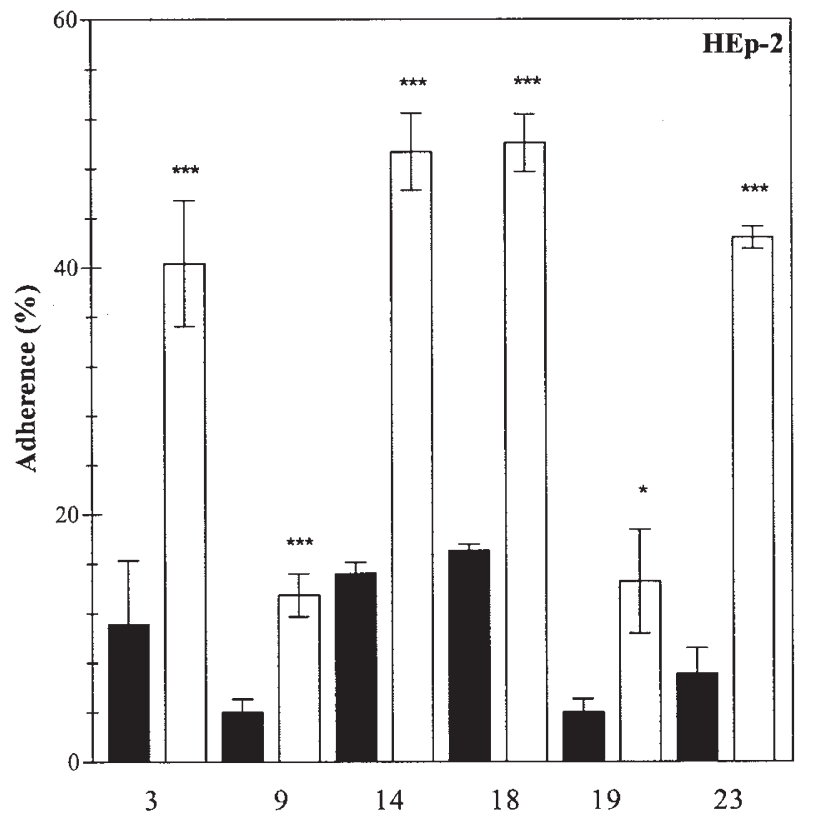

B

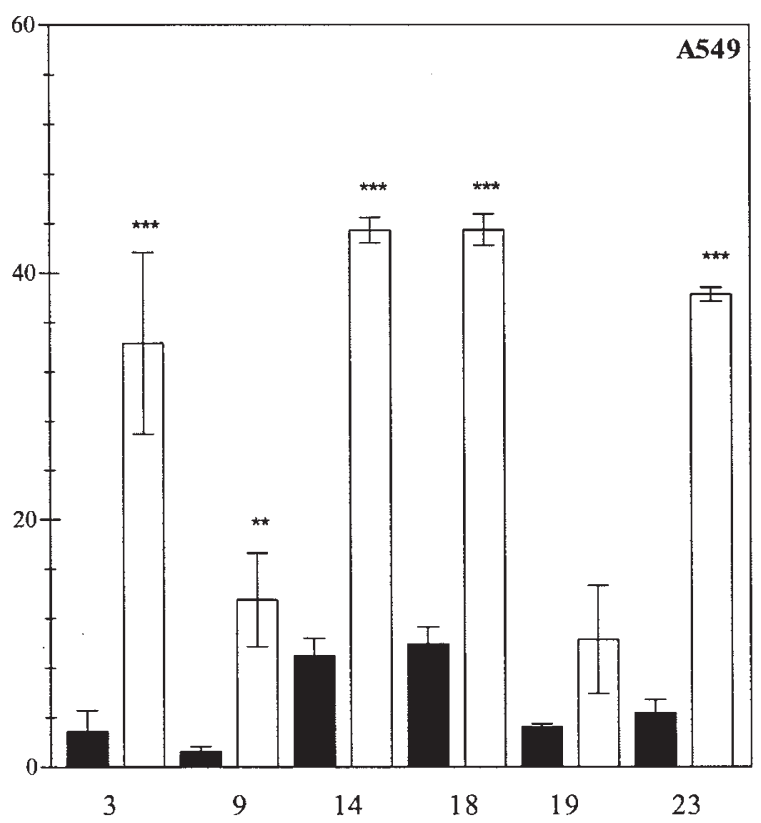

Figure 3. Adherence of heat-killed S. pneumoniae serotypes 3, 9, 14, 18, 19, and 23 to uninfected and RSV-infected HEp-2 and A549 cells as measured by the cytometric fluorescence assay. (A) Filled bars: percentage of pneumococcal adherence to uninfected HEp-2 monolayers; open bars: percentage of maximally enhanced pneumococcal adherence to RSV-infected HEp-2 cells (with logarithmic viral dilutions varying between 3.2 and 3.8). (B) Filled bars: percentage of pneumococcal adherence to uninfected A549 monolayers; open bars: percentage of maximal enhanced pneumococcal adherence to RSV-infected A549 cells (with logarithmic viral dilutions varying between 3.0 and 3.2). Error bars represent SEM of three experiments; ${ }^{*} p<0.05$, ** $p<0.01, * * * p<0.001$ (significance assessed by $t$ test). 
After washing away unbound antibodies, cells were resuspended in PBS $(2+)$. Fluorescence per cell was analyzed in a FACScan flowcytometer (BD Biosciences, San Jose, CA, U.S.A.). Per sample, 5000 cells were analyzed. The fluorescence of test samples was compared with the fluorescence of control samples by setting a marker at the end of the autofluorescence peak of the control cells. Fluorescence beyond the marker was attributed to antibodies attached to the cells. Percentages of positive cells are depicted in the figures.

Cytometric fluorescence adherence assay. The assay was adapted from a CytoFluor assay (Applied Biosystems, Foster City, CA, U.S.A.) described by Tamura et al. (17).

Medium was removed from RSV-infected or uninfected monolayers of HEp-2/A549 cells in culture plates and $50 \mu \mathrm{L}$ of FITC-labeled bacteria were added. The plates were spun at 160 $\times g$ for $10 \mathrm{~min}$ in a plate spinner (IEC Centra $3 \mathrm{C}$, Thermo Electron Oy, Vantaa, Finland) to allow the pneumococci to near the monolayers. Next, the plates were incubated at $21^{\circ} \mathrm{C}$ for $30 \mathrm{~min}$. Total fluorescence was measured by a fluorescence multi-well plate reader (CytoFluor, Applied Biosystems), with an excitation wave length of $485 \mathrm{~nm}$, an emission filter of 530 $\mathrm{nm}$, gain setting of 54 , and three readings per well. Subsequently, the wells were washed four times with PBS $(2+)$ to remove unbound bacteria. After having added $50 \mu \mathrm{L}$ PBS $(2+)$, final fluorescence was measured. Adherence percentages were calculated as final/total fluorescence $\times 100$.

CFU-based adherence assay. Medium was removed from 24-well plates with RSV-infected and uninfected HEp-2 cells and $250 \mu \mathrm{L}$ of FITC-labeled or unlabeled live bacteria were added to each well. Subsequently, the plates were centrifuged at $160 \times g$ for $10 \mathrm{~min}$ in a plate spinner. Next, the plates were incubated at $21^{\circ} \mathrm{C}$ for $30 \mathrm{~min}$. Thereafter, the plates were

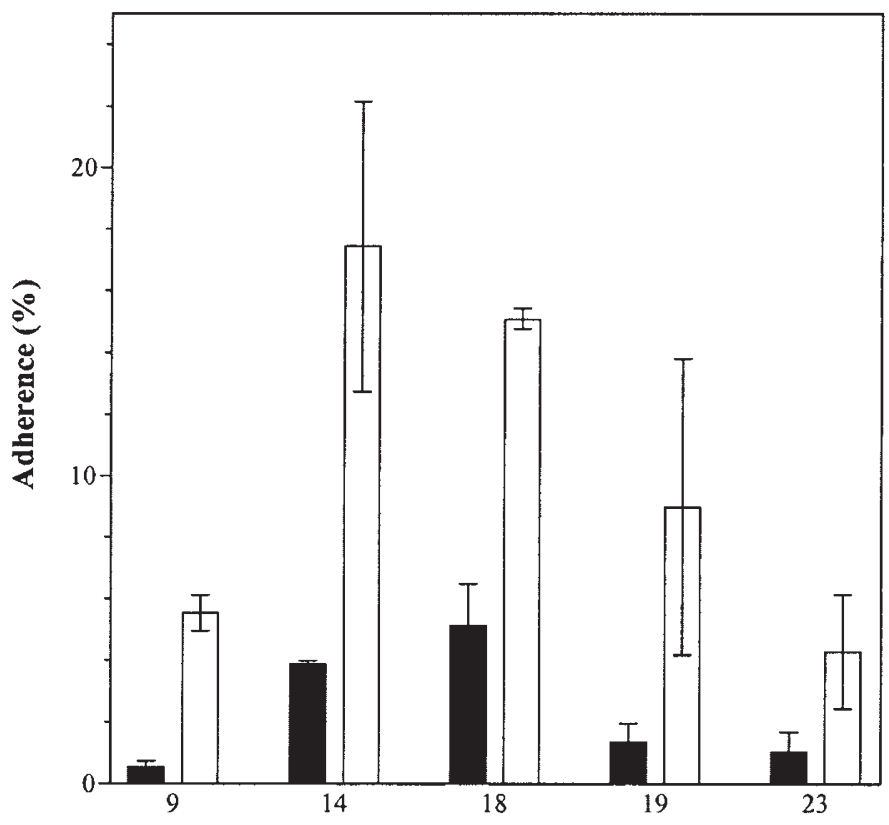

Figure 4. Adherence of live S. pneumoniae serotypes 9, 14, 18, 19, and 23 to uninfected and RSV-infected HEp-2 cells as measured by the CFU assay. Open bars: percentage of pneumococcal adherence to uninfected cells; filled bars: percentage of maximal enhanced pneumococcal adherence to RSV-infected cells. Error bars represent means and SD of duplicate samples. washed four times with PBS $(2+)$ to remove unbound bacteria. To each well, $75 \mu \mathrm{L}$ trypsin was added to detach the monolayers. From this mixture of detached cells with bacteria, a suspension of $250 \mu \mathrm{L}$ was prepared by adding $175 \mu \mathrm{L}$ PBS.

$\mathrm{CFU}$ of the original bacterial suspension (total CFU) and of the suspension after the adherence assay (final CFU) were estimated by the CFU-counting method. In summary, from a bacterial suspension, a serial dilution of 1:10 in saline was prepared. Of each dilution, $10 \mu \mathrm{L}$ was plated on a pre-dried blood-agar plate. After overnight incubation in a $\mathrm{CO}_{2}$ incubator at $37^{\circ} \mathrm{C}$, CFU could be counted separately at several dilutions. The bacterial concentration $(\mathrm{CFU} / \mathrm{mL})$ was calculated as $\mathrm{CFU} \times$ dilution $\times 10(10 \mu \mathrm{L} / \mathrm{spot})$. Adherence percentages was calculated as final CFU/total CFU $\times 100$.

Scanning electron microscopy. HEp-2 cells were infected with RSV and grown as monolayers on fibrinogen-coated glass coverslips in 24-well microtiter plates (Costar). Fifty microliters of a suspension of unlabeled heat-killed bacteria was added to the cells and the mixture was incubated for $30 \mathrm{~min}$ after centrifugation (160 $\mathrm{g}$ at $10 \mathrm{~min})$. Plates were washed twice with PBS $(2+)$ and twice with PBS. Glutaraldehyde 2\% (Merck, Darmstadt, Germany) in phosphate buffer $0.1 \mathrm{M}, \mathrm{pH}$ 7.4 was added to each sample to fix the bacteria and cells. After $1 \mathrm{~h}$, glutaraldehyde was removed and samples were dehydrated in ethanol $(80 \%)$. After dehydration, hexamethyldisilazane (Fluka Chemical Corp., Ronkonkoma, NY, U.S.A.) was added to each specimen. After drying, samples were glued on a specimen mount with carbon-based glue (CCC-adhesive, Electron Microscopy Sciences, Hatfield, PA, U.S.A.). Samples were gold-sputtered (Sputter Coater 208HR, Cressington Scientific Instruments Ltd., Watford, U.K.) and examined with a scanning electron microscope (Royal Philips Electronics, Eindhoven, The Netherlands).

Statistics. Quantification of RSV infection by immunofluorescence was performed with duplicate samples, and mean values of one representative experiment were given in the results. Cytometric fluorescence adherence experiments were performed thrice. Each individual cytometric fluorescence adherence experiment was measured 7 -fold. The figures depict means and standard errors of the three independent cytometric fluorescence adherence tests. CFU-based adherence assays were performed with duplicate samples and means of these samples were depicted in the figures. The significance of different values was calculated by $t$ test. Differences with $p$ values $<0.05$ were considered significant

\section{RESULTS}

Detection of RSV-infected cells by immunofluorescence (fluorescence-activated cell scanner). Figure 1 shows the percentages of RSV-positive cells of the infected HEp-2 and A549 monolayers, at d 3-5 post-RSV infection. As a result of progressive RSV infection, CPE occurred. At d 4 post-RSV infection, with logarithmic viral dilutions ranging from 3.0 to 3.4 (MOI ranging from $1.25 \times 10^{-1}$ to $5.0 \times 10^{-2}$ ), almost $80 \%$ of the HEp- 2 and $55 \%$ of A549 cells were RSV-positive whereas epithelial monolayers showed minimal microscopic 


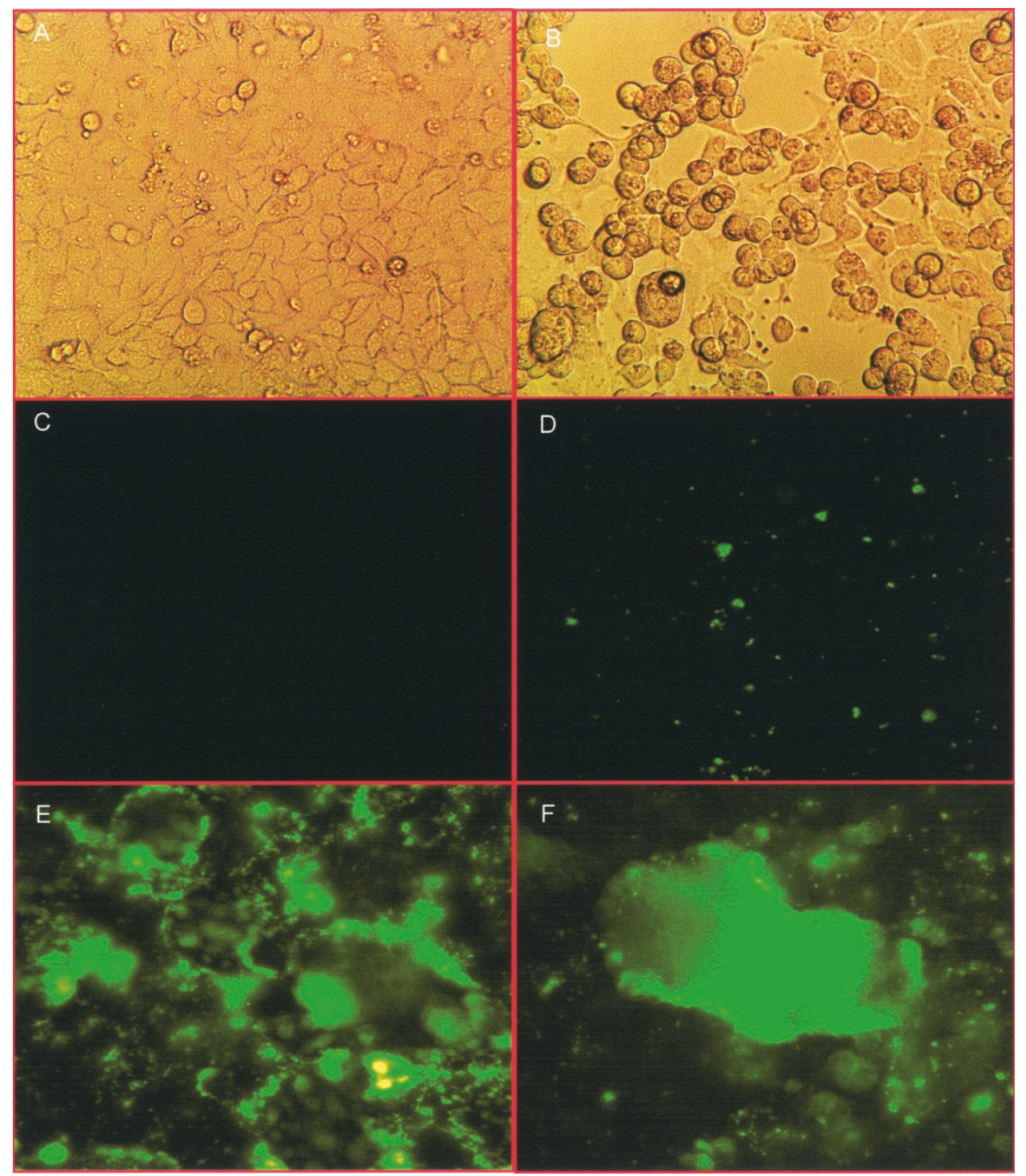

Figure 5. (A) Light microscopy: monolayer of uninfected HEp-2 cells. (B) Light microscopy: monolayer of HEp-2 cells showing extensive CPE with syncytia formation. (C) Fluorescence microscopy: background fluorescence of HEp-2 monolayer without pneumococci. (D) Fluorescence microscopy: FITC-labeled heat-killed pneumococci adhering to an uninfected HEp-2 monolayer. $(E)$ Fluorescence microscopy: pneumococcal adherence to an RSV-infected monolayer of HEp-2 cells. $(F)$ Fluorescence microscopy: syncytium with attached pneumococci. Magnification of all fluorescence micrographs: $400 \times$.

signs of CPE. Therefore, in adherence experiments described below, 4-d-old RSV-infected monolayers were used.

Adherence of heat-killed pneumococci to RSV-infected HEp-2 and A549 cells. Adherence of pneumococcal serotypes $3,9,14,18,19$, and 23 was tested on RSV-infected monolayers of HEp-2 and A549 cells with logarithmic viral doses ranging from 3.0 to 5.0 , correlating with viral MOI of $1.25 \times 10^{-1}$ to $1.25 \times 10^{-3}$. HEp-2 monolayers showed more extensive CPE at relatively lower viral doses compared with A549 monolayers. Adherence percentages were found to be dependent on both RSV infection dose and the degree of CPE in the monolayers (Fig. 2). Figure 3 depicts the maximal enhanced pneumococcal adherence due to RSV infection (with viral dilutions ranging from 3.0 to 3.6) of all serotypes. Depending on the pneumococcal serotype, adherence to A549 cells increased 3to 10-fold due to RSV infection, whereas for HEp-2 cells adherence increased 2- to 5-fold.
Adherence of live pneumococci to RSV-infected HEp-2 cells. As a control for our findings with heat-killed pneumococci, we performed a CFU-based adherence assay with live pneumococci. Monolayers were incubated with live, unlabeled pneumococci. After trypsinizing the monolayers with attached pneumococci, cell-bacteria mixtures were plated to count CFU the next day. Adherence percentages of live bacteria (serotypes $9,14,18,19,23$ ) were generally lower compared with adherence percentages of heat-killed pneumococci tested in a cytometric fluorescence assay. After RSV infection, however, all serotypes showed strongly increased adherence to HEp-2 monolayers (Fig. 4).

Visualization of pneumococcal adherence by fuorescence and scanning microscopy. Heat-killed FITC-labeled pneumococci could be seen attached to uninfected HEp-2 cells in a randomly distributed pattern. In contrast, RSV-infected HEp-2 cells showed a more intense fluorescence pattern due to higher 


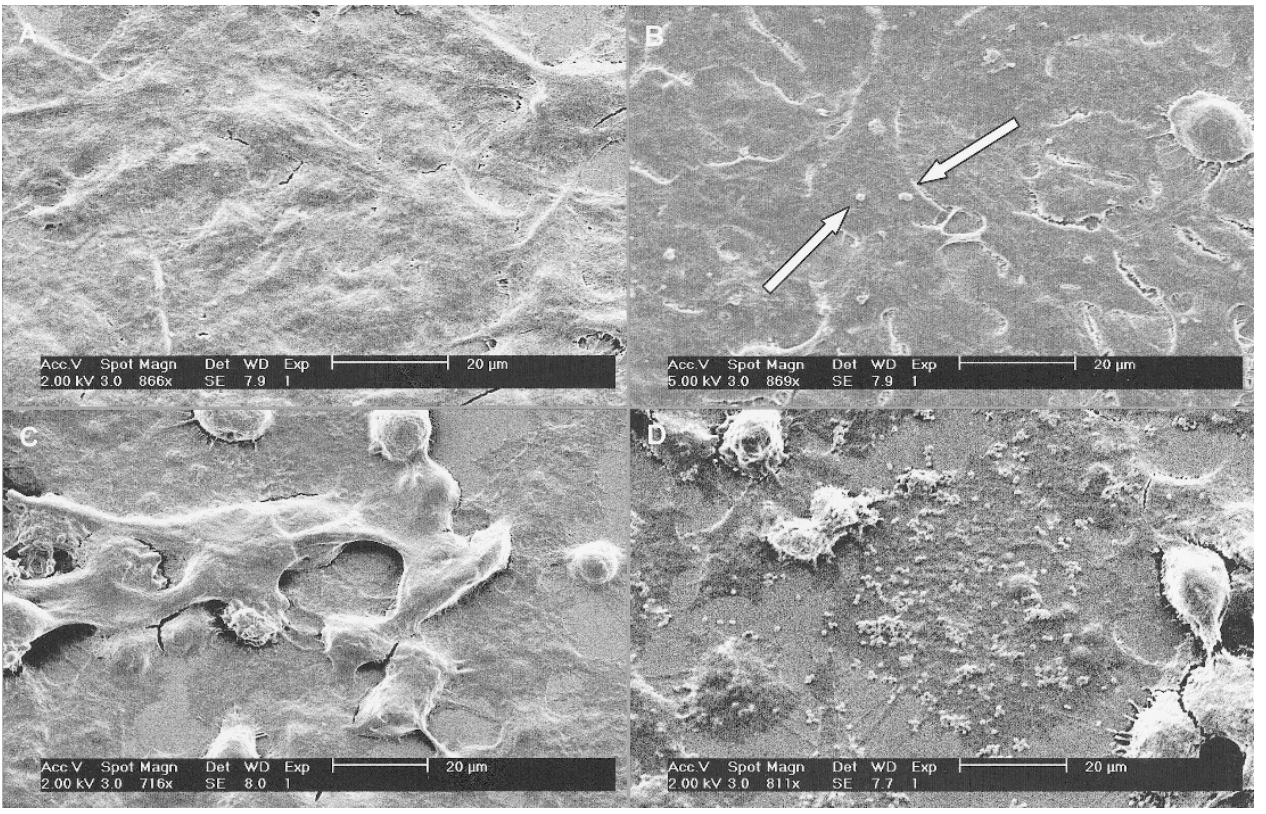

Figure 6. Scanning electron micrographs. (A) Control monolayer of uninfected HEp-2 cells (magnification $866 \times)$, without pneumococci. $(B)$ Monolayer of uninfected HEp-2 cells with attached heat-killed pneumococci (white arrows) (magnification $869 \times$ ). (C) RSV-infected monolayer showing disruption of integrity of monolayer and syncytia formation (magnification 716×). (D) RSV-infected monolayer of HEp-2 cells with adherent heat-killed pneumococci (magnification $811 \times)$.

concentrations of adherent pneumococci. In addition, we observed a dense accumulation of FITC-labeled pneumococci to syncytia (Fig. 5).

By scanning electron microscopy, RSV-infected HEp-2 monolayers showed high numbers of heat-killed pneumococci attached to individual epithelial cells. Again, dense accumulations of pneumococci could be observed attached to syncytia (Fig. 6).

\section{DISCUSSION}

Worldwide, S. pneumoniae and RSV are the most prevalent pathogens causing upper and lower respiratory tract infection in infants and young children $(1,2)$. In recent years, a number of publications reported that both pathogens were associated with each other, causing infections concurrently and synergistically $(7-10,18)$.

Enhanced bacterial adherence to virus-infected epithelium is considered an important first event leading to bacterial superinfection (19-24). In the present study, we found that RSV infection of human epithelial cells leads to increased adherence of the most pathogenic pneumococcal serotypes in childhood.

Various in vitro and in vivo studies have focused on the increased bacterial adherence after a preceding viral infection $(25,26)$. Certain strains of S. pneumoniae were found to adhere in greater numbers to A549 cells infected with adenovirus compared with uninfected A549 cells (22). Furthermore, it was found that RSV infection of epithelial cells may lead to enhanced adherence of Hemophilus influenzae, Neisseria meningitidis, Bordetella pertussis, and Staphylococcus aureus (24, 27, 28).

Despite the clinical relevance, only a single study has addressed the adherence of $S$. pneumoniae to epithelial cells in relation to RSV infection (29). The authors found that several pneumococcal serotypes, causing respiratory infections and meningitis, adhered better after RSV infection of trypsinized HEp-2 cells in a fluid-phase assay by flow cytometry. In the present study, a cytometric fluorescence assay was used to study pneumococcal adherence to epithelial monolayers, creating a more physiologic condition. In addition, experiments with A549 (pneumocyte type II) cells were included, as A549 cells are more representative for human epithelium of the lower respiratory tract than HEp-2 cells.

We found that RSV infection enhanced pneumococcal adherence to both cell types. This effect was most pronounced in experiments with A549 cells. Although pneumococcal adherence to uninfected A549 cells is less extensive than to HEp-2 cells, adherence to both cell types increased strongly upon RSV infection. This phenomenon is probably clinically relevant for pneumococcal respiratory-tract infections facilitated by preceding RSV infections.

For the use in the cytometric fluorescence assay, heat-killed pneumococci were used. With live pneumococci, however, we similarly found a strongly enhanced adherence after RSV infection of HEp-2 cells.

Compared with heat-killed bacteria, live pneumococci appeared to adhere less well to epithelial cells. This difference may be due to the fact that live pneumococci have a more dense polysaccharide capsule, possibly impairing exposure of adhesins.

There are several possible mechanisms by which increased pneumococcal adherence to RSV-infected cells could be explained. Firstly, viral glycoproteins expressed on the infected host cell may act as receptors for pneumococci. Secondly, RSV infection may up-regulate molecules on the host-cell mem- 
brane that may function as pneumococcal receptors. Another possibility could be that the phenomenon described in the present study is a result of a mixture of these mechanisms, working additively or synergistically.

In the binding of meningococci to RSV-infected HEp-2 cells, both viral glycoprotein $\mathrm{G}$ and immunologic markers CD14 and CD18 have been identified as bacterial receptors $(29,30)$.

Wang et al. (31) have shown that RSV infection of A549 cells leads to increased expression of intercellular adhesion molecule-1 (CD54), vascular adhesion molecule-1 (CD106) and E-cadherin (CD117). Blockade with mono- and polyclonal antibodies directed to CD14, CD18, CD54, CD106, and CD117, however, did not inhibit enhanced pneumococcal adherence in our assay.

In further, preliminary experiments, we have obtained evidence that anti-RSV polyclonal antibodies blocked the enhancement of pneumococcal adherence due to RSV infection (data not shown). This is in line with the idea that viral (glyco-) proteins can mediate pneumococcal attachment to RSVinfected epithelium. However, further study is needed to elucidate the mechanism of the enhanced pneumococcal binding to RSV-infected cells.

In conclusion, we have shown that pneumococcal adherence to human respiratory cells is enhanced by a preceding RSV infection. These findings are in accordance with the concept that viral infections enhance bacterial adherence to the local epithelium, thereby facilitating bacterial superinfection.

\section{REFERENCES}

1. Centers for Disease Control and Prevention 2001 From the Centers for Disease Control and Prevention. Respiratory syncytial virus activity-United States, 1999 2000 season. JAMA 285:287-288

2. Robinson KA, Baughman W, Rothrock G, Barrett NL, Pass M, Lexau C, Damaske B, Stefonek K, Barnes B, Patterson J, Zell ER, Schuchat A, Whitney CG 2001 Epidemiology of invasive Streptococcus pneumoniae infections in the United States, 1995-1998: opportunities for prevention in the conjugate vaccine era. JAMA 285:1729-1735

3. Hament JM, Kimpen JL, Fleer A, Wolfs TF 1999 Respiratory viral infection predisposing for bacterial disease: a concise review. FEMS Immunol Med Microbiol 26:189-195

4. Heikkinen T 2000 The role of respiratory viruses in otitis media. Vaccine 19:S51-S55

5. Chonmaitree T, Heikkinen T 2000 Viruses and acute otitis media. Pediatr Infect Dis J 19:1005-1007

6. Heikkinen T, Chonmaitree T 2000 Viral-bacterial synergy in otitis media: implications for management. Curr Infect Dis Rep 2:154-159

7. Andrade MA, Hoberman A, Glustein J, Paradise JL, Wald ER 1998 Acute otitis media in children with bronchiolitis. Pediatrics 101:617-619

8. Chonmaitree T, Henrickson KJ 2000 Detection of respiratory viruses in the middle ear fluids of children with acute otitis media by multiplex reverse transcription: polymerase chain reaction assay. Pediatr Infect Dis J 19:258-260
9. Kim PE, Musher DM, Glezen WP, Rodriguez-Barradas MC, Nahm WK, Wright CE 1996 Association of invasive pneumococcal disease with season, atmospheric conditions, air pollution, and the isolation of respiratory viruses. Clin Infect Dis 22:100106

10. Heiskanen-Kosma T, Korppi M, Jokinen C, Kurki S, Heiskanen L, Juvonen H, Kallinen S, Sten M, Tarkiainen A, Ronnberg PR, Kleemola M, Makela PH, Leinonen M 1998 Etiology of childhood pneumonia: serologic results of a prospective, population-based study. Pediatr Infect Dis J 17:986-991

11. Butler JC, Breiman RF, Lipman HB, Hofmann J, Facklam RR 1995 Serotype distribution of Streptococcus pneumoniae infections among preschool children in the United States, 1978-1994: implications for development of a conjugate vaccine. J Infect Dis 171:885-889

12. Gray BM, Converse GM, Dillon Jr HC 1979 Serotypes of Streptococcus pneumoniae causing disease. J Infect Dis 140:979-983

13. Kalin M 1998 Pneumococcal serotypes and their clinical relevance. Thorax 53:159162

14. Rumke HC, Hermans PWM, Bogaert D, de Groot R 2002 Pneumokokken vaccinatie van jonge kinderen in het Rijkvacinatieprogramma? Infectie Bulletin 12:217-223

15. Sanford BA, Smith N, Shelokov A, Ramsay MA 1979 Adherence of group-B streptococci and human erythrocytes to influenza A virus-infected MDCK cells. Proc Soc Exp Biol Med 160:226-232

16. Fainstein V, Musher DM, Cate TR 1980 Bacterial adherence to pharyngeal cells during viral infection. J Infect Dis 141:172-176

17. Tamura GS, Kuypers JM, Smith S, Raff H, Rubens CE 1994 Adherence of group-B streptococci to cultured epithelial cells: roles of environmental factors and bacterial surface components. Infect Immun 62:2450-2458

18. Heikkinen T 2000 Role of viruses in the pathogenesis of acute otitis media. Pediatr Infect Dis J 19:S17-S22

19. Bakaletz LO, Hoepf TM, DeMaria TF, Lim DJ 1988 The effect of antecedent influenza A virus infection on the adherence of Hemophilus influenzae to chinchilla tracheal epithelium. Am J Otolaryngol 9:127-134

20. Bakaletz LO, 1995 Viral potentiation of bacterial superinfection of the respiratory tract. Trends Microbiol 3:110-114

21. Saadi AT, Blackwell CC, Raza MW, James VS, Stewart J, Elton RA, Weir DM 1993 Factors enhancing adherence of toxigenic Staphylococcus aureus to epithelial cells and their possible role in sudden infant death syndrome. Epidemiol Infect 110:507517

22. Hakansson A, Kidd A, Wadell G, Sabharwal H, Svanborg C 1994 Adenovirus infection enhances in vitro adherence of Streptococcus pneumoniae. Infect Immun 62:2707-2714

23. El Ahmer OR, Raza MW, Ogilvie MM, Weir DM, Blackwell CC 1999 Binding of bacteria to $\mathrm{HEp}-2$ cells infected with influenza A virus. FEMS Immunol Med Microbiol 23:331-341

24. Patel J, Faden H, Sharma S, Ogra PL 1992 Effect of respiratory syncytial virus on adherence, colonization and immunity of non-typable Haemophilus influenzae: implications for otitis media. Int J Pediatr Otorhinolaryngol 23:15-23

25. Davison VE, Sanford BA 1981 Adherence of Staphylococcus aureus to influenza A virus-infected Madin-Darby canine kidney cell cultures. Infect Immun 32:118-126

26. Sanford BA, Shelokov A, Ramsay MA 1978 Bacterial adherence to virus-infected cells: a cell culture model of bacterial superinfection. J Infect Dis 137:176-181

27. Saadi AT, Blackwell CC, Essery SD, Raza MW, El Ahmer OR, MacKenzie DA, James VS, Weir DM, Ogilvie MM, Elton RA, Busuttil A, Keeling JW 1996 Developmental and environmental factors that enhance binding of Bordetella pertussis to human epithelial cells in relation to sudden infant death syndrome (SIDS). FEMS Immunol Med Microbiol 16:51-59

28. Raza MW, Ogilvie MM, Blackwell CC, Stewart J, Elton RA, Weir DM 1993 Effect of respiratory syncytial virus infection on binding of Neisseria meningitidis and Haemophilus influenzae type b to a human epithelial cell line (HEp-2). Epidemiol Infect 110:339-347

29. Elahmer OR, Raza MW, Ogilvie MM, Blackwell CC, Weir DM, Elton RA 1996 The effect of respiratory virus infection on expression of cell surface antigens associated with binding of potentially pathogenic bacteria. Adv Exp Med Biol 408:169-177

30. Raza MW, Blackwell CC, Ogilvie MM, Saadi AT, Stewart J, Elton RA, Weir DM 1994 Evidence for the role of glycoprotein G of respiratory syncytial virus in binding of Neisseria meningitidis to HEp-2 cells. FEMS Immunol Med Microbiol 10:25-30

31. Wang SZ, Hallsworth PG, Dowling KD, Alpers JH, Bowden JJ, Forsyth KD 2000 Adhesion molecule expression on epithelial cells infected with respiratory syncytial virus. Eur Respir J 15:358-366 